\title{
Evaluating the relationship between financial sustainability and socio-economic development of countries
}

Viktoriia Kremen, Inna Shkolnyk, Andrii Semenog, Olha Kremen

To cite this article: Kremen, V., Shkolnyk, I., Semenog, A., \& Kremen, O. (2019). Evaluating the relationship between financial sustainability and socio-economic development of countries. Central European Economic Journal, 6(53), 25-38.

DOI: $10.2478 /$ ceej-2019-0003.

To link to this article: https://doi.org/10.2478/ceej-2019-0003 


\title{
Central European Economic Journal
}

\author{
Viktoriia Kremen ${ }^{1}$ (D) Inna Shkolnyk ${ }^{2}$ Andrii Semenog ${ }^{2}$ (D) Olha Kremen ${ }^{3}$ \\ 1 National Transport University Kyiv, Ukraine, corresponding author: kremenviktori@gmail.com \\ 2 Sumy State University, Ukraine \\ 3 Kyiv National University of Technologies and Design, Ukraine
}

\section{Evaluating the Relationship Between Financial Sustainability and Socio-Economic Development of Countries}

\begin{abstract}
This paper examines the mainstream theories of "financial sustainability" and "financial development". It is suggested understanding "financial development" as the complex dynamic characteristics of the financial sector, which is formed under the influence of financial and economic policy factors and the financial market functioning. The paper provides the methodology of relationship between financial sustainability and socio-economic development of countries evaluation. Based on the matrix method, it is proved that the differences in developed and developing countries occur due to the relationship between financial sustainability and financial development.
\end{abstract}

Keywords: financial sustainability, socio-economic development, financial development, financial sector, financial market

JEL Codes: G20, G28, O16

\section{Introduction}

Along with such a characteristic of the financial sector as sustainability, an important aspect of the financial sector functioning is its development, which eventually ensures its positive impact on the country's economic growth. Alternatively, financial stability is associated with limitation of risks - credit, investment, currency, interest and so on, and the formation of increased volumes of equity that correspond to these risks. On the other hand, the activity of financial intermediaries is based on the assumption of financial risks and aspirations for the least possible immobilization of capital. We can assume that by limiting the activities of financial intermediaries, we restrict their financial development (FD), and, as a result, the development of the financial market. This, in turn, can hold back the economic growth of countries, which is not enough lately and difficult to achieve. Consequently, by transforming super- visory practices and requirements to financial intermediaries, financial supervisors are in the constant search for a balance between financial sustainability and FD. They compare the negative effect of slowing financial market development and the possible reduction of gross domestic product (GDP) because of inevitable increased financial sustainability and financial crisis losses if the financial sector is not sustained.

\section{Literature review}

The complexity of developing criteria for financial sustainability is determined by the absence of unity in understanding the concept and types of "system stability". Thus, The Financial Sector Assessment Program, 2018 of the International Monetary Fund (IMF) and World Bank (FSAP) involves assessing the reliability of individual subsystems (the banking system in the first 
place), the quality of the banking, insurance, financial markets and supervision of international standards, conducting stress tests, evaluating the ability of monetary authorities to react effectively in case of systemic stress. However, it does not reveal the notion of the financial system and financial sector stability.

According to Eatweal, Milgate, and Mewman (1998), the system is considered to be stable if, when disturbed, it deviates slightly from the state of equilibrium, and all subsequent movements remain relatively in short distances from equilibrium. But very often for a dynamic system, the equilibrium can have a multiple expression. The widespread emergence of a multiple equilibrium in the economy made scientists introduce the concept of stability in the process of adaptation and quasi-stability. The process of adaptation is believed to be globally stable, if for any initial state there is an equilibrium point to which the system directs - this point should not be the same for all initial conditions. Quasi-stability is characterized by the construction of a sequence of points from any starting point, which transmits a sequence of time going to infinity, and all these points are points of equilibrium.

The Professor of the School of Business at Columbia University, Mishkin (1999), believes that financial instability occurs when the financial system is shocked and informed in a way that it can no longer transform savings into investments.

The representative of the IMF (Schinasi, 2006) outlines that financial stability is a situation in which the financial system is capable to fulfil three key functions simultaneously. Firstly, the financial system effectively and continuously favours the intermittent allocation of resources in the economy from owners of savings to investors and distribution of economic resources in general. Secondly, financial risks for the future are determined and evaluated with acceptable accuracy and are relatively well-managed. Thirdly, the financial system is in such a situation that is capable to absorb financial and real economic shocks. According to the expert, the financial system is in a state of stability when it contributes to the functioning of the economy and dissipates financial imbalances that arise endogenously or because of significant negative and unpredictable events. This approach to understanding financial sustainability requires the proper work of financial institutions, financial markets, financial infrastructure and the financial sector as a whole, and emphasizes such an important prerequisite for financial sector sustainability as risk assessment and risk management.
Foot (2003) from the Office of Financial Regulation and Supervision of Great Britain suggests understanding the financial stability from the following positions: (a) monetary (price) stability; (b) the approximation of the employment level in the economy to the natural level; (c) trust to economic operations of key financial institutions and markets; (d) the absence of a negative effect of the prices on real and financial assets movement in the economy on (a) or (b). This approach is based on the fact that the basis for financial sustainability is the stability of financial markets functioning, price stability and the monetary system stability.

Crockett (1997), a representative of the Bank for International Settlements and the Financial Stability Forum, holds the view that financial stability can be defined as a lack of instability. It is a situation in which economic activity potentially weakens fluctuations in prices on financial assets or the inability of financial institutions to comply with contractual obligations.

Chant, Lai, Illing, and Daniel (2003), advisors of the Bank of Canada, also consider it expedient to consider the essence of financial stability as contradictory to financial instability - the situation on financial markets that impedes or threatens economic activity.

Ferguson (2002), a member of the Board of Governors of the Federal Reserve, also studies financial instability determined by three criteria: (1) prices for key financial assets that deviate significantly from the fundamental values; (2) failures in the functioning of securities markets and access to credit in the country and at the international level; (3) aggregate expenditures significantly deviating from the potential value.

The research and systematization of scientific and methodological approaches to the definition of the essence of the concept of "financial development" have shown a lack of a unified approach to its content. In most scientific works, the concept of "financial development" is considered as improving the functions of the financial system or the development of financial institutions. In most studies, FD is limited to specific quantitative indicators that characterize the size of the financial assets of the banking sector or the stock market, while the attention is not drawn to the stability of the financial sector, which does not correspond to the theoretical basis of understanding of FD. Therefore, there is a need for a holistic and integrated formulation of a scientific and methodological approach to assess the relationship between FD of the country and the stability of the financial sector. 
It should be noted that in the modern economic literature, the concept "financial development" is often identified with the concept "financial sector development". Levine (2004) was one of the first to draw attention to the study of this concept. He points out that FD occurs only when financial instruments, markets and intermediaries begin to perform their functions better. There is improvement in the production of prior information about possible investment, investment monitoring and corporate governance, trade, diversification and risk management, mobilization and distribution of savings, exchange and trade in goods and services. Each of these functions can have an impact on increasing savings and making investment decisions and thereby promoting economic growth. The same opinion is shared by Čihák, Demirgüč-Kunt, Feyen, and Levine (2013), who mention FD as the basis for the functions of the financial sector improvement. Moreover, they believe that an assessment of the level of financial sector development should be based on measuring its four characteristics: the size (depth) - the total number of services provided by financial institutions; access - the breadth of individual financial services use, efficiency and sustainability.

Another interpretation of the concept "financial development" is presented in the Financial Development Report (World Economic Forum, 2012). According to this document, FD is a set of factors, economic policy and a system of legal institutions that promote more efficient financial intermediation, a deeper and wider access to capital and financial services. We suppose that the above interpretation is incomplete because the term "development" means a process characterized by dynamic, as well as transition from one qualitative level to another, accompanied by qualitative, quantitative and structural changes.

Therefore, we suggest understanding "financial development" as the complex dynamic characteristics of the financial sector, which is formed under the influence of financial and economic policy factors and the financial market functioning. It is a process of improvement of the financial intermediation efficiency and the availability of capital and financial services for major economic actors.

In this context, it should be noted that over the past two decades there has been a series of scientific works and econometric studies that examine the relationship between FD of countries, the rates of their economic growth and the stability level of the financial sector.

The WEF report "Balancing Financial Stability, Innovation, and Economic Growth" (World Econo- mic Forum, 2017) deals with the need for a balance between financial stability, innovation and economic development. The study notes that along with wellknown sources of systemic risk in the financial sector, which include credit bubbles, mismatches of deadlines, the functioning of industries, the volatility of financial markets, new sources have appeared. They are cyberrisks, the development of critical infrastructure and the dependence of infrastructure elements. The WEF also emphasizes that the expected changes in innovation will bring significant benefits to the financial sector, but it requires joint actions devoted to the availability of financial services, risk management improvement, standardization of Fintech companies' activities that are more active in creating added value.

Bordo and Meissner (2015) conducted a study to answer the question "Why did some countries learn to achieve financial sustainability, and others did not?" The authors explore key determinants and major political responses to banking, currency and debt crises between 1880 and present days in such countries as the USA, Canada, Brazil and Argentina. The authors also analysed the relation between money supply and GDP for such groups of countries as leaders, learners and non-learners. As a result of the research, the authors came to the conclusion that countries' financial sustainability level differs because of the rule of law, democracy, political stability and other institutional differences between the countries.

Almarzoqi, Naceur, and Kotak (2015) conducted a study attempting to find out what is important for FD and sustainability. The authors identified measures that could influence such aspects of the financial institutions' development as depth, efficiency and sustainability. Also, based on the theory of frontier financial possibilities, scholars identified the gap between the actual and foreseen levels of FD. After calculations, the authors came to the conclusion that the level of inflation, the level of openness of the country's economy, the quality of risk management and banking crises make a great influence on FD.

The purpose of scientific research made by Cree, Hubert, and Labondance (2013) was to establish a link between economic indicators, financial depth and financial stability in the European Union in 1998-2011. The authors emphasize that the traditional vision financial depth positively affects the economic efficiency (components of aggregated consumption, investment or available income) - is not confirmed for European countries. Using various measures of financial instability 
(institutional index, microeconomic indicators and own statistical index, derived from the analysis of key components) they found that financial instability negatively affects economic growth.

Batuo, Mlambo, and Asongu (2017) conducted a thorough study of the interrelationships between FD, financial instability, financial liberalization and economic growth in African countries. Based on the calculations, the researchers came to the conclusion that FD and financial liberalization contribute to financial instability, while economic growth reduces financial instability, and the level of such decline is much greater in the periods before financial liberalization than in post-liberalization periods.

Carbó-Valverde and Pedauga (2013) in the issue devoted to the crisis, the risk and stability of the financial markets investigated the relationship between the financial sector development of the country and its rates of economic growth, which allowed to identify the channels of financial instability influence on the interconnection between financial sector development of the country and its economic growth.

\section{Methodology}

Improving prudential financial supervision requires the assessment and monitoring of the strength and vulnerability of the financial system at the macroeconomic level. For this, the IMF developed a system of financial sustainability indicators: current financial health and strength of countries' financial institutions and their counterparties - corporations and households. Indicators include both aggregated information about individual institutions activities and indicators that characterize the markets where financial institutions operate. The set of financial sustainability indicators includes the ones that characterize the level of development of other financial corporations, non-financial corporations, households, securities market and real estate market (Tab. 1).

As a result of a detailed analysis of the system of financial stability indicators developed by the IMF and the experience of its practical use in many countries of the world, it can be argued that its benefits are the calculation of indicators on a quarterly and annual basis. One should take into account the peculiarities of functioning not only the financial sector but also non-financial corporations, households and the real estate market, the use of indicators of financial sustainability in stress tests and macroprudential analysis. The disadvantages include the duplication of some indicators by others, the difficulty of formulating conclusions through a multivectoral change in various indicators, the lack of normative values of indicators and, the lack of calculations of some indicators in different countries.

We have selected the countries and indicators based on the existing IMF statistical base (Financial Soundness Indicators: Compilation Guide, 2018). For a comprehensive assessment of financial sustainability, we selected seven developed countries - Austria, Great Britain, Canada, Germany, Poland, the United States and the Czech Republic, and seven developing countries Georgia, Kazakhstan, South Africa, Russian Federation, Romania, Turkey and Ukraine.

To carry out a generalized assessment of financial sustainability of these countries in 2009-2017, the following indicators were used:

- I01 - ratio of regulatory capital and risk-weighted assets;

- I02 - ratio of level I regulatory capital and risk-weighted assets;

- I04 - capital share in assets;

- I05 - share of non-performing loans less provisions in the total amount of capital;

- I06 - share of non-performing loans in the total amount of loans;

- $\quad$ I08 - division of loans by sectors, share in total loans

- $\quad$ I09 - return on assets;

- I10 - equity profitability;

- I11 - share of interest margin in gross income;

- I12 - share of non-interest expenses in gross income;

- $\quad$ I13 - share of liquid assets in total assets;

- I14 - share of liquid assets and short-term liabilities;

- $\quad$ I23 - share of staff costs and non-interest expenses;

- $\quad$ I26 - ratio of customer deposits (excluding interbank loans) and total loans;

- I27 - share of loans in foreign currency in the total amount of loans;

- I28 - share of liabilities in foreign currency in the total amount of liabilities.

Taking into account that all the above indicators are measured in percent, for a generalized assessment of financial stability of the country, their values do not require standardization. Consequently, for each country, we obtain a matrix of output data, in which each indicator of financial stability $\operatorname{FSI}_{i}(i=\overline{1,16})$ for a certain amount of time $t(t=\overline{1, T})$ becomes value $f s i_{i t}$. 
Tab 1: Indicators of financial sustainability for different institutional sectors and markets

\section{Key indicators of financial stability of depository institutions}

I01 Ratio of regulatory capital and risk-weighted assets

I02 Ratio of regulatory capital of level I and risk-weighted assets

103 Equity ratio and risk-weighted assets

104 Capital share in assets

105 The share of non-performing loans less provisions in the total amount of capital

106 The share of non-performing loans in the total amount of loans

107 Reserves for non-performing loans

108 Distribution of loans by sectors, share in total loans

109 Return on assets

110 Return on equity

I11 Percentage interest margin in gross income

112 Percentage of non-interest expenses in gross income

113 Share of liquid assets in the total assets

114 Value of liquid assets and short-term liabilities

I15 Value of affordable stable financing and necessary stable financing

I16 Ratio of net open position in foreign currency and capital

\section{Additional indicators of the real estate market}

117 Ratio of regulatory capital and risk-weighted assets

\section{Additional indicators of financial stability of depository institutions}

118 Ratio of large risks and capital

119 Geographical distribution of loans by sectors, share in total loans

I20 Ratio of gross position of financial derivatives in assets and capital

I21 Ratio of the gross position of financial derivatives in liabilities and equity

122 Share of income from financial instruments purchase and sale operations in gross income

123 Share of staff costs at non-interest expenses

124 Spread between interest rates on loans and deposit rates

I25 Spread between the highest and lowest interbank rates

I26 The ratio of customer deposits (excluding interbank loans) and total loans

127 The share of loans in foreign currency in the total amount of loans

128 The share of liabilities in foreign currency in the total amount of liabilities

129 The growth rate of loans to the private sector

\section{Indicators of financial stability of other financial corporations}

130 The share of assets in the total assets of the financial system

I31 Value of assets and GDP

\section{Indicators of financial stability of funds in the money market}

132 Breakdown of investments by sectors, share in total investment

133 Breakdown of terms of investment, share in total investment

\section{Indicators of financial stability of insurance companies}

I34 Value of equity and investment assets

I35 The ratio of received premiums minus premiums transferred by primary insurers to the total amount of premiums received

136 Return on assets

I37 Return on equity

\section{Indicators of financial stability of pension funds}

137 The ratio of liquid assets and projected retirement benefits next year

139 Return on assets

\section{Indicators of financial stability of non-financial corporations}

140 The ratio of debt and equity

141 Return on assets

142 Return on equity 
Tab 1: Indicators of financial sustainability for different institutional sectors and markets (continue)

\begin{tabular}{|c|c|}
\hline \multicolumn{2}{|r|}{ Indicators of financial stability of non-financial corporations } \\
\hline 143 & The ratio of income and expenses for debt servicing and repayment \\
\hline 144 & Ratio of income and interest expense \\
\hline 145 & Share of liquid assets in the total assets amount Number of bankruptcy cases \\
\hline 146 & The ratio of debt capital and GDP \\
\hline \multicolumn{2}{|c|}{ Indicators of financial sustainability of households } \\
\hline 147 & The ratio of household debt and GDP \\
\hline 148 & The ratio of payments by households to debt servicing and repayment and income \\
\hline 149 & The ratio of household boron and household income \\
\hline \multicolumn{2}{|r|}{ Indicators of financial stability of the real estate market } \\
\hline 150 & Dynamics of prices for commercial real estate \\
\hline 151 & The share of loans for residential real estate in the total amount of loans \\
\hline 152 & The share of loans for commercial real estate in the total amount of loans \\
\hline
\end{tabular}

GDP, gross domestic product.

Source: data from International Monetary Fund, 2018.

At the next step, we construct a standard- point $E F S I=\left(e f s i_{1}, e f s i_{2}, \ldots, e f s i_{n}\right)$. We determine its coordinates if the growth of the financial stability indicator shows an increase in financial stability of the country, and its decrease - reduction of the country's financial stability as follows:

efsi $i_{i}=\max _{t=1 \div T}\left\{f s i_{i t}\right\}$

If the growth of the financial stability indicator shows a decrease in financial stability of the country, and its decrease - increasing financial stability of the country, then the coordinate standard point is determined by the formula:

efsi $i_{i}=\min _{t=1 \div T}\left\{e f s i_{i t}\right\}$

Based on the analytical nature of financial stability indicators, formula (1) was applied to the indicators I01, I02, I04, I08, I09, I10, I11, I13, I14, I26, and formula (2) was used for indicators I05, I06, I12, I23, I27, I28, I51.

We used the Euclidean distance method to find the distance $l_{t}$ for each country between that point $E F S I=\left(e f s i_{1}, e f s i_{2}, \ldots, e f s i_{n}\right)$ and every point $C=\left(f s i_{1 t^{\prime}} f s i_{2 t^{\prime}} \ldots, f s i_{i n}\right)$ for each period $t$ :

$$
l_{t}=\sqrt{\sum\left(f s i_{i n}-f s i_{n}\right)^{2}}
$$

Based on the obtained distance value for the period $t$, we define a comprehensive index of financial stability of the country $F S_{t}$ :

$F S_{t}=1-\frac{l_{t}}{\bar{l}+m \sigma_{l}}$

where $\bar{l}$ - arithmetic mean $l_{t}$ for the studied period of time; $\sigma_{l}$ - mean square deviation $l_{i} ; m$ - same positive number, which is chosen to be 2 or 3 - so that the value $F S_{t}$ was in range $[0 ; 1]$.

It should be noted that since 2008 the WEF annually has been publishing Global Competitiveness Report that represents the global competitiveness index for more than 130 countries. It is worth noting that this indicator is complex and, in its calculations, WEF specialists take into account the assessment of the basic requirements, the amplifiers of efficiency and innovations (Fig. 1).

We must admit that the pillar 8 "Financial market development" occupies 17\% in the index of global competitiveness. The development of the financial market is a complex indicator of financial services availability, ease of access to credit resources, the availability of venture capital, stability of banking institutions, stock exchange regulation and rights protection. For each country according to pillar 8, we determine the importance of category and rank in the overall rating. The maximum value of the global competitiveness index categories and the index itself varies from 1 to 7 (Schwab, 2017).

In order to combine evaluation and tracking the relationship between the financial sector's soundness and the FD of the country, we suggest applying a matrix 
Global Competitiveness Index

Basic requirements subindex

Pillar 1. Institutions

Pillar 2. Infrastructure

Pillar 3. Macroeconomic environment

Pillar 4. Health and primary education

\section{Efficiency enhancers subindex}

Pillar 5. Higher education and training

Pillar 6. Goods market efficiency

Pillar 7. Labor market efficiency

Pillar 8. Financial market development

Pillar 9. Technological readiness

Pillar 10. Market size

Fig1. Categories of global competitiveness index. Source: Schwab (2017).

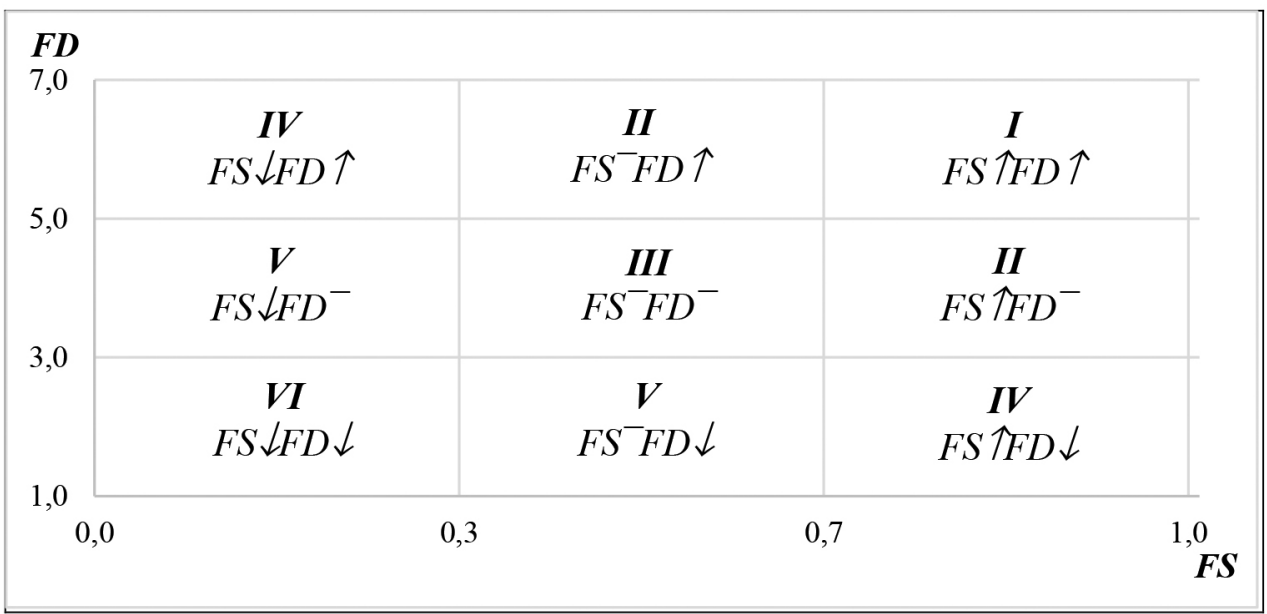

Fig2. Categories of global competitiveness index. Source: Own elaboration.

approach. The proposed approach is based on the construction of the FD-financial soundness matrix, which will combine these critical characteristics of the country's financial sector and assess the relationship between the level of financial sustainability and FD of the countries.

Fig. 2 shows a layout of the proposed FD-FS matrix, which allows countries to be divided according to the values of a comprehensive indicator of financial stability and the pillar 8 "Financial market development" of the Global Competitiveness Index. According to the figure, a country can fit into one of the nine sectors of the matrix, which should be grouped into clusters.
The clusters differ from each other and are characterized by the following parameters:

- Cluster I includes countries that have a high level of financial stability and FD (FS $\uparrow F D \uparrow)$;

- Cluster II combines countries with an average level of financial sustainability and high FD (FS $\leftrightarrow$ FD $\uparrow)$ and a high level of financial sustainability and

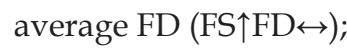

- Cluster III - countries that have an average level of FD and financial sustainability $(\mathrm{FS} \leftrightarrow \mathrm{FD} \leftrightarrow)$;

- Cluster IV - the country entries into this cluster if one of the characteristics of the financial sector is high and the other one is low (FS $\downarrow F D \uparrow, F S \uparrow F D \downarrow$ ); 
- Cluster V unites countries in which one of the characteristics of the financial sector has an average level, and the other one is low (FS $\downarrow$ FD $\uparrow, F S \uparrow F D \downarrow$ );

- Cluster VI includes countries that are characterized by low levels of financial sustainability and $\mathrm{FD}(\mathrm{FS} \downarrow \mathrm{FD} \downarrow)$.

The issues that require further resolution include the study of the relationship between financial sustainability and socio-economic development in the context of groups of developing and developed countries. The methodology of studying the impact of financial sector sustainability on indicators of socio-economic development, considering that financial stability is a qualitative feature, should be based on the use of nonparametric methods of research. It should consider the requirements that must be observed in order to solve this scientific task:

- necessity of ensuring comparability of the research data and the unity of the information base, for which all indicators were taken from the statistical database of the IMF;

- a comprehensive illustration of the socio-economic development of countries - for this purpose we used absolute indicators (GDP, money supply, gold reserves, IMF loans (only for developing countries only), high-tech exports, foreign direct investments (net cash flow) and relative indicators (interest rate on deposits, real interest rate on loans, consumer price index, share of financial sector loans to residents in GDP, unemployment rate);

- the use of simple and unambiguous nonparametric methods for establishing the relationship between the features, in particular the Fechner coefficient and the Spirman rank correlation coefficient.

Fechner Signs Correlation Coefficient, allowing you to estimate the interconnection tightness and its direction, is calculated by the formula:

$F=\frac{N^{+}-N^{-}}{N^{+}+N^{-}}$

where $F$ - coefficient Fechner; $N^{+}$- the number of coincidence of signs deviations from average; $N^{-}$- the number of mismatch of signs deviations from average.

We indicated the above absolute and relative indicators of socio-economic development of countries as $s e_{i}$. If inequality:

$s e_{i} \geq \overline{s e}$ or

$F S_{i} \geq \overline{F S}$

is performed, the value is assigned " + " sign, otherwise the sign is "-". In the case when the signs are the same on both indicators, it is a coincidence, and when they are different, there is a mismatch.

The estimation of the statistical significance of the Fechner coefficient was carried out on the basis of the Student's criterion:

$t_{F}=F \sqrt{\frac{n-2}{1-F^{2}}}$

A comparison $t_{F}$ with a tabular value $t_{\text {tabul }}(n-m-1 ; a)$ allows determining the significance $\left(t_{F}>t_{\text {tabul }}\right)$ or insignificance $\left(t_{F}<t_{\text {tabul }}\right)$ of the Fechner coefficient. On the basis of the Fechner coefficient values, which must be in the interval $[-1 ; 1]$, we determined the strength and the direction of the relationship between financial sustainability and socio-economic development of developing and developed countries. The strength of the relationship is estimated by the following algorithm: if $|F| \rightarrow 0$, so, the relationship is weak, and if $|F| \rightarrow 1$ it is tight. The direction of the relationship between financial sustainability and socio-economic development is identified as direct if $F>0$, or as inverse if $F<0$.

It is believed that, in comparison with the Fechner coefficient, Spearman's Rank-Order Correlation coefficient gives more accurate values. It is calculated by the formula:

$\rho=1-\frac{6 \sum d_{i}^{2}}{n\left(n^{2}-1\right)}$

where $\rho$ - Spearman coefficient; $d_{i}$ - difference of ranks of factor and result indicators; $n$ - number of pairs of ranks.

However, as the practice of statistical calculations shows, the coefficients of Fechner and Spearman are basically mutually consistent and coincide in the interpretation in the part of the direction of communication. To assess the statistical significance of the Spearman rank correlation coefficient, it was necessary to find the critical point

$t_{\rho \text { tabul }}\left(n-m-1 ; \frac{a}{2}\right)$, 
on the basis of which, for a given probability, degrees of freedom $d f=n-2$, we calculated the critical value by the formula:

$t_{\rho}=t_{\rho \text { tabul }} \sqrt{\frac{1-\rho^{2}}{n-2}}$

If $|\rho|<t_{\rho}$, then Spearman's coefficient is statistically insignificant, and if $|\rho|>t_{\rho^{\prime}}$, the coefficient is significant. Based on the results of calculations of the Spearman rank correlation coefficient, we made an analysis of the strength and direction of the relationship between financial sustainability and socio-economic development of developing and developed countries. The values of the Spearman rank correlation coefficient must be in the range $[-1 ; 1]$. If $|\rho| \rightarrow 0,3$, so the relationship is practically absent, but if $|\rho| \rightarrow 1$ - it is tight and strong. If $\rho>0$, the relationship is direct, if $\rho<0$, it is inverse relationship.

To assess the tightness of the relationship between financial sustainability and socio-economic development in developing and developed countries, we used the Schedule of Chaddock, based on the values of the coefficients of Fechner and Spearman.

\section{Results}

The construction of the FD-FS matrix for the 14 countries under study in 2009-2017 has shown that none of these countries was included to clusters I FS $\uparrow F D \uparrow$, II FS $\uparrow \mathrm{FD}^{-}$, IV FS $\uparrow F D \downarrow$ and $V_{\text {FS }}{ }^{-}$FD $\downarrow$. This means that between 2009 and 2017, among the countries selected for research, there were no such countries with a low level of FD and a high level of financial sustainability (Fig. 3).

The analysis of the country's position in clusters of the matrix FD-FS in 2009-2017 showed that Austria, the Czech Republic, the Russian Federation, Romania and Turkey were in the cluster with an average level of financial sustainability and an average level of FD (III FS ${ }^{-} \mathrm{FD}^{-}$). During the study period, the situation with financial sustainability and FD in Poland and Georgia did not change. These countries belonged to the cluster with low financial stability and medium FD (V FS $\downarrow \mathrm{FD}^{-}$).

Such countries as Germany, the United States and Kazakhstan demonstrated an improvement in the relationship between financial sustainability and FD. During 2009-2016, Germany had an average level of financial sustainability and FD (III FS ${ }^{-} \mathrm{FD}^{-}$). The increase in the level of FD in 2017 allowed this country to enter almost the best cluster with average financial sustainability and high FD (II FS ${ }^{-}$FD $\uparrow$ ). In 2009, Kazakhstan was in the cluster of low financial sustainability and medium $\mathrm{FD}\left(\mathrm{V} \mathrm{FS} \downarrow^{-} \mathrm{FD}^{-}\right)$, but the country has improved its financial sustainability since 2010 and entered the cluster III $\mathrm{FS}^{-} \mathrm{FD}^{-}$. In 2009-2011, the United States was in the cluster with an average level of financial sustainability and average FD (III FS ${ }^{-}$FD $^{-}$), but in 2012-2017, they demonstrated an increase in FD and moved to the II FS ${ }^{-} \mathrm{FD} \uparrow$ cluster.

Canada and South Africa have shown a deterioration in the relationship between financial sustainability and FD over the period under review. In 2009-2011, Canada, having the average level of financial sustainability and high level of FD corresponding to the matrix cluster II FS ${ }^{-} \mathrm{FD} \uparrow$, received a decline in financial sustainability and moved to the IV FS $\downarrow$ FD $\uparrow$ cluster. South Africa during 2009-2016 was part of the cluster of countries with a low level of financial sustainability and a high level of FD, and in 2017, due to a decline in FD entered the V FS $\downarrow F^{-}$cluster. That was a tendency where low financial stability over time leads to a decrease in FD.

Diverse trends in terms of financial sustainability and FD during 2009-2017 took place in the UK and in Ukraine. In 2009-2011, the United Kingdom had a low level of financial sustainability and medium FD (V FS $\left.\downarrow F^{-}\right)$, however, in 2012-2014, the level of FD was high, and the country joined the IV FS $\downarrow$ FD $\uparrow$ cluster. In 2015, the United Kingdom had negative dynamics of FD, which turned it into the V FS $\downarrow \mathrm{FD}^{-}$cluster, however, in 2017, the country again entered the cluster with low financial sustainability, but with high FD (IV FS $\downarrow$ FD $\uparrow$ ). In 2009, Ukraine had a low level of financial sustainability and an average level of FD and entered the cluster $\mathrm{V}$ FS $\downarrow \mathrm{FD}^{-}$. In 2010-2013, the country managed to improve the situation by increasing its financial stability, which transferred it into the III $\mathrm{FS}^{-} \mathrm{FD}^{-}$cluster. But, in 2014-2015, there was a decline in financial sustainability and the country returned to the cluster V FS $\downarrow \mathrm{FD}^{-}$. In 2016, the negative trend for Ukraine continued as a decline in FD. As a result, the country entered the worst cluster VI FS $\downarrow$ FD $\downarrow$. In 2017, the tendency of FD and financial stability reduction stopped, so the country moved into the cluster with an average level of financial sustainability and FD (III FS ${ }^{-} \mathrm{FD}^{-}$).

Overall, developing countries showed low financial sustainability combined with low and medium FD, or average financial sustainability with an average level of FD. During the study period, developed countries 


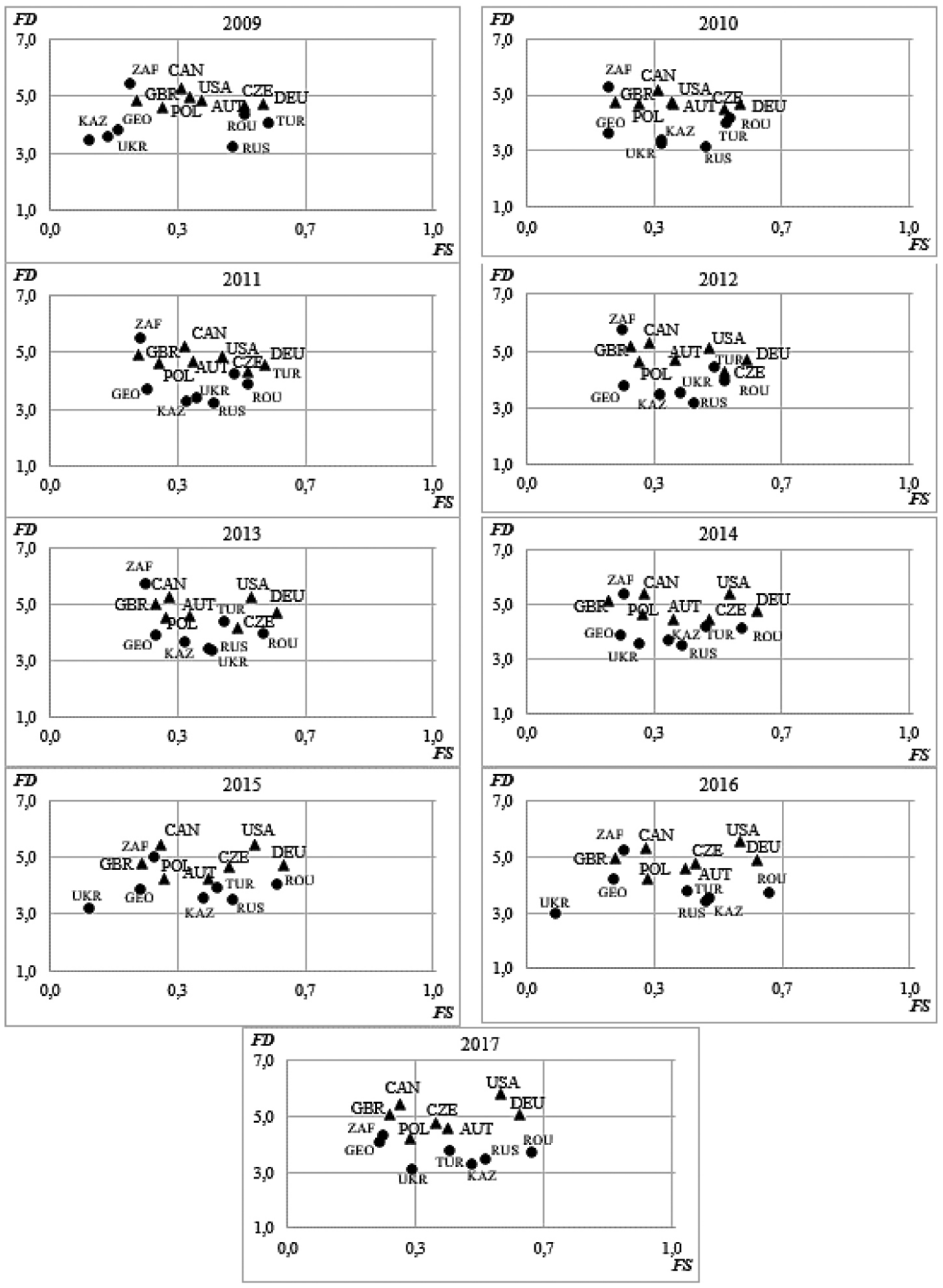

Fig. 3. Countries of the world on the FD-FS matrix in 2009-2017. Source: Own elaboration. Note: $\Delta$ - developed countries: AUT Austria, CZE - Czech Republic, GBR - Great Britain, CAN - Canada, DEU - Deutschland, POL - Poland, USA - United States of America, • - developing countries: GEO - Georgia, KAZ - Kazakhstan, ZAF - South Africa, RUS - Russian Federation, ROU Romania, TUR - Turkey, UKR - Ukraine. 
Tab. 2: The impact of financial sustainability on the social and economic development of developing and developed countries in 2009-2016

\begin{tabular}{|c|c|c|c|c|c|c|c|}
\hline \multirow[t]{2}{*}{ No. } & \multirow[t]{2}{*}{ Indicator } & \multicolumn{3}{|c|}{ Developing countries } & \multicolumn{3}{|c|}{ Developed countries } \\
\hline & & Result & Criteria & Direction of connection & Result & Criteria & Direction of connection \\
\hline \multirow[t]{3}{*}{1} & GDP, \$ & & & & & & \\
\hline & Fehner & -0.39 & 3.14 & $\downarrow \downarrow$ & $0.14^{*}$ & 1.06 & - \\
\hline & Spearman & $-0.06^{*}$ & 0.27 & - & 0.43 & 0.25 & $\uparrow \uparrow$ \\
\hline \multirow[t]{3}{*}{2} & Money sup & & & & & & \\
\hline & Fehner & $0.00^{*}$ & $0.13^{*}$ & - & $-0.06^{*}$ & 0.42 & - \\
\hline & Spearman & 0.00 & 0.27 & - & 0.34 & 0.34 & $\uparrow \uparrow$ \\
\hline \multirow[t]{3}{*}{3} & Gold and $\mathrm{c}$ & cy reserv & & & & & \\
\hline & Fehner & $-0.04^{*}$ & 0.26 & - & $-0.07^{*}$ & 0.53 & - \\
\hline & Spearman & $0.02 *$ & 0.27 & - & $-0.26^{*}$ & 0.26 & - \\
\hline \multirow[t]{3}{*}{4} & Use of IMF & & & & & & \\
\hline & Fehner & 0.43 & 3.49 & $\uparrow \uparrow$ & - & - & - \\
\hline & Spearman & $0.24^{*}$ & 0.26 & - & - & - & - \\
\hline \multirow[t]{3}{*}{5} & High-tech & & & & & & \\
\hline & Fehner & 0.46 & 3.85 & $\uparrow \uparrow$ & $-0.18^{*}$ & 1.33 & - \\
\hline & Spearman & 0.56 & 0.23 & $\uparrow \uparrow \uparrow$ & -0.67 & 0.20 & - \\
\hline \multirow[t]{3}{*}{6} & Direct forei & vestment & t flow), \$ & & & & \\
\hline & Fehner & 0.36 & 2.81 & $\uparrow \uparrow$ & $-0.07^{*}$ & 0.53 & - \\
\hline & Spearman & 0.35 & 0.25 & $\uparrow \uparrow$ & $-0.14^{*}$ & 0.27 & - \\
\hline \multirow[t]{3}{*}{7} & Interest rat & leposits,? & & & & & \\
\hline & Fehner & $-0.08^{*}$ & 0.57 & - & 0.75 & 4.24 & $\uparrow \uparrow \uparrow \uparrow$ \\
\hline & Spearman & $-0.08^{*}$ & 0.3 & - & 0.74 & 0.39 & $\uparrow \uparrow \uparrow \uparrow$ \\
\hline \multirow[t]{3}{*}{8} & Real intere & on loans & & & & & \\
\hline & Fehner & $0.25^{*}$ & 1.59 & - & $0.25^{*}$ & 1.21 & - \\
\hline & Spearman & $0.27^{*}$ & 0.32 & - & $0.30^{*}$ & 0.42 & - \\
\hline \multirow[t]{3}{*}{9} & Financial se & oans to $r$ & nts, $\%$ ВBП & & & & \\
\hline & Fehner & -0.29 & 2.19 & $\downarrow$ & $0.05^{*}$ & 0.30 & - \\
\hline & Spearman & -0.45 & 0.24 & $\downarrow \downarrow$ & $0.08^{*}$ & 0.57 & - \\
\hline \multirow[t]{3}{*}{10} & Consumer & index, $\%$ з & & & & & \\
\hline & Fehner & $0.04^{*}$ & 0.26 & - & -0.25 & 1.90 & $\downarrow$ \\
\hline & Spearman & $-0.10^{*}$ & 0.27 & - & $-0.24^{*}$ & 0.26 & - \\
\hline \multirow[t]{3}{*}{11} & Unemployr & rate, $\%$ & & & & & \\
\hline & Fehner & -0.54 & 4.66 & $\downarrow \downarrow \downarrow$ & -0.36 & 2.81 & $\downarrow \downarrow$ \\
\hline & Spearman & -0.50 & 0.24 & $\downarrow \downarrow \downarrow$ & -0.45 & 0.24 & $\downarrow \downarrow$ \\
\hline
\end{tabular}

GDP, gross domestic product.

Source: Own calculations based on data from the International Monetary Fund and World Bank.

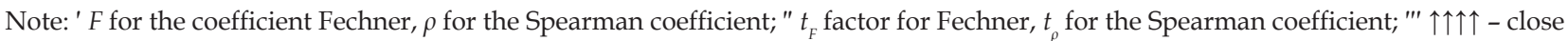
straight, $\uparrow \uparrow \uparrow$ - visible straight, $\downarrow \downarrow \downarrow$ - noticeable inverse, $\uparrow \uparrow$ - moderate straight line, $\downarrow \downarrow$ - moderate inverse, $\downarrow$ - weak inverted; *indicates the insignificance of the coefficients of Fechner and Spearman. 
managed to combine low and medium financial sustainability with medium and high level of FD. That is why, the level of development of the country affects its level of FD and does not affect its level of financial sustainability.

The results of calculating the values of Fechner and Spearman coefficients, criteria of their significance allowed us to determine the nature of the relationship between financial sustainability and socio-economic development of developed countries and developing countries (Tab. 2).

The calculations were made using the data of socio-economic development of seven countries (both developed and developing countries) for 8 years (2009-2016). According the Student's tables we found that

$t_{\text {tabul }}(56-1-1 ; 0,05)=t_{\text {tabul }}(54 ; 0,05)=1,67$.

The estimation of the essentialness of the Spierman coefficient required the determination of a critical value that could not be calculated without a critical point

$t_{\rho \text { tabul }}\left(56-1-1 ; \frac{0,05}{2}\right)=t_{\rho \text { tabul }}\left(54 ; \frac{0,05}{2}\right)=2,00$.

The obtained values allowed us to evaluate the significance of the Fechner and Spearman coefficients.

According to the Fechner coefficient, in developed countries, there is a close direct relationship between financial stability and interest rates on deposits, a moderate inverse relationship between financial stability and unemployment, a weak inverse relationship between financial stability and the consumer price index. That means that the growth of financial stability in developed countries leads to an increase in interest rates on deposits, lower unemployment and inflation in the consumer market, and vice versa. In developing countries, there is a moderate direct relationship between financial sustainability and IMF loans, high-tech exports and foreign direct investment, and a moderate inverse relationship between financial sustainability and GDP, the inverse relationship between financial stability and unemployment, weak inverse relationship between the financial stability and the share of loans to the financial sector residents in GDP. Thus, the growth of financial stability in developing countries leads to an increase in IMF loans, high-tech exports and foreign direct investment, reduction of GDP, credits to the economy and unemployment.

According to the Spearman coefficient, in developed countries there is a close direct relationship between financial stability and interest rate on deposits; moderate direct interconnection between financial stability and GDP, the money supply; a moderate inverse relationship between financial stability and unemployment. Therefore, the growth of financial stability in developed countries can increase GDP, money supply, interest rates on deposits and reduce unemployment.

In developing countries, there is a close direct relationship between financial sustainability and high-tech exports; moderate direct relationship between financial stability and direct foreign investment; a inverse relationship between financial stability and unemployment; a moderate inverse relationship between financial stability and the share of financial sector loans to residents in GDP. That means that increasing financial sustainability in developing countries contributes to the growth of high-tech exports, foreign direct investment and reduces unemployment, constraining the volume of lending by the financial sector to residents.

\section{Conclusions}

None of the countries during the investigated period had either high financial stability or high FD, while a low level of FD was observed at the same time as a low level of financial sustainability. So, the high level of financial stability of the country remains unattainable for any level of FD even the high one. The low level of financial stability of the countries was observed in combination with low, medium and high level of FD, and the average level of financial stability - with medium and high levels of FD. The level of development of the country affects its level of FD and does not affect its level of financial stability. Low financial sustainability leads to a decrease in the level of FD of the country. In contrast to FD, financial stability can be improved only in a few countries in the short and medium term.

The assessment of the relationship between financial sustainability and indicators of socio-economic development of countries showed that in developed countries the growth of financial sustainability contributes to increasing the volume of GDP, money supply, interest rates on deposits and decreasing inflation. While in developing countries, the growth of financial sustainability leads to an increase in IMF lending, high-tech exports, foreign direct investment and decrease in the financial sector lending to the economy. In both groups of the countries, the growth of financial stability provides a reduction in the unemployment rate of the economically active population. 


\section{References}

[1] Almarzoqi, R., Naceur, S., \& Kotak, A. (2015). What matters for financial development and stability? (IMF Working Papers, Working Paper No. 15/173). Retrieved from International Monetary Fund: https://www.imf.org/external/pubs/ft/ wp/2015/wp15173.pdf.

[2] Batuo, M., Mlambo, K., \& Asongu, S. (2017). Linkages between financial development, financial instability, financial liberalisation and economic growth in Africa. Research in International Business and Finance, 45, 168-179.

[3] Bordo, M., \& Meissner, C. (2015). Growing up to stability? Financial globalization, financial development and financial crises (NBER Working Paper, Working Paper No. 21287). Retrieved from National Bureau of Economic Research: http://www. nber.org/papers/w21287.pdf.

[4] Carbó-Valverde, S., \& Pedauga, L. (2013). Financial stability and economic growth. In J.F. de Guevara Radoselovics \& J.M.P. Monsálvez (Eds.), Crisis, risk and stability in financial markets (pp. 8-23). London, England: Palgrave Macmillan.

[5] Chant, J., Lai, A., Illing, M., \& Daniel, F. (2003). Essays on financial stability. Canada: Bank of Canada.

[6] Čihák, M., Demirgüč-Kunt, A., Feyen, E., \& Levine, R. (2013). Financial development in 205 economies, 1960 to 2010 (NBER Working Paper, Working Paper No. 18946). Retrieved from National Bureau of Economic Research: http:/ / www.nber. org/papers/w18946.pdf

[7] Cree, J., Hubert, P., \& Labondance, F. (2013). Financial stability and economic performance. Retrieved from HAL: https:/ / hal-sciencespo.archives-ouvertes.fr/hal-01064263/document.

[8] Crockett, A. (1997). The theory and practice of financial stability. Retrieved from www.princeton.edu: https://www. princeton.edu/ ies/IES_Essays/E203.pdf.

[9] Eatweal, J., Milgate, M., \& Mewman, P. (1998). The new Palgrave a dictionary of economics. London, England: Macmillan Reference Ltd.

[10] Ferguson, R. (2002). Should financial stability be an explicit central bank objective? Retrieved from International Monetary Fund: https:/ /www.imf.org/external/pubs/ft/ seminar/2002/gfs/eng/ferguson.pdf.

[11] Financial Soundness Indicators: Compilation Guide. (2018). Retrieved from International Monetary Fund: https://www. imf.org/external/pubs/ft/fsi/guide/2006/index.htm.

[12] Financial Soundness Indicators (FSIs)/IMF Data Access to Macroeconomic \& Financial Data. (2018). Retrieved from International Monetary Fund: http:/ / data.imf.org/regular. aspx?key=61404590.

[13] Foot, M. (2003). What is 'financial stability' and how do we get it? London, England: The Roy Bridge Memorial Lecture, Financial Services Authority.

[14] Heath, R. (2013). Modifications to the current list of financial soundness indicators. Retrieved from International Monetary Fund: https://www.imf.org/external/np/pp/ eng/2013/111313.pdf.

[15] Levine, R. (2004). Finance and growth: Theory and evidence (NBER Working Paper, Working Paper No. 10766). Retrieved from National Bureau of Economic Research: http:/ /www. nber.org/papers/w10766.pdf.
[16] Mishkin, F.S. (1999). Global financial instability: Framework, events, issues. Journal of Economic Perspectives, 13(4), 3-20.

[17] Schinasi, G. (2004). Defining financial stability (IMF Working papers, Working Paper No. WP/04/187). Retrieved from International Monetary Fund: https:/ / www.imf.org/ external/pubs/ft/wp/2004/wp04187.pdf.

[18] Schinasi, G. (2006). Safeguarding financial stability: Theory and practice. Washington, DC: International Monetary Fund, Publication Services.

[19] Schwab, K. (2017). The global competitiveness report (Rep.). Retrieved from World Economic Forum: http://www3. weforum.org/docs/GCR2017-2018/05FullReport/ TheGlobalCompetitivenessReport2017\%E2\%80\%932018.pdf.

[20] The Financial Sector Assessment Program. (2018). Retrieved from International Monetary Fund: https:/ / www.imf.org/ external/np/fsap/fsap.aspx.

[21] World Bank: Free and open access to global development data. (2018). Retrieved from World Bank: https:/ / data. worldbank.org/.

[22] World Economic Forum. (2012). The financial development report (Rep.). Retrieved from World Economic Forum: http:/ / reports.weforum.org/financial-development-report-2012/\#section $=$ contributors.

[23] World Economic Forum. (2017). Balancing financial stability, innovation, and economic growth (Rep.). Retrieved from World Economic Forum: http://www3.weforum.org/docs/ IP/2017/FS/WEF_Whitepaper_FSIEG.pdf. 